\title{
A respeito da renovação/reabilitação urbana: da Europa à América Latina, da América Latina à Europa.
}

\author{
Hélène Rivière d'Arc
}

Tradução: Cibele Saliba Rizek

Socióloga, professora doutora do Departamento de Arquitetura e Urbanismo da EESC-USP, Av. Trabalhador Sancarlense, 400, Centro, CEP 13566-590, São Carlos, SP, (16) 3373-9822, cibele@uol.com.br

ostaria, de início, de me situar na ótica dos pesquisadores que se colocam na perspectiva da "volta à cidade" não apenas como um remédio para seus males, mas como uma tendência estrutural que combina o econômico e o cultural, bem como o social, em um processo que dá destaque tanto a um horizonte utópico como a uma vontade política. A multiplicação dos programas de revitalização, além da reabilitação constitui, ao que me parece, um substrato metodológico suficiente para essa afirmação. Assim, sem ser prescritiva ou mesmo submeter o futuro a um pré-julgamento, prefiro recorrer mais a Jane Jacobs e à sua insistência na defesa da diversidade das grandes cidades, do que a Melvin Webber e sua focalização nas redes, monotonia espacial e a um nonplace urban realm, que apaga os lugares bem como o imaginário e a materialidade que os criam. Recorro a esses autores norte americanos porque acredito que é nos Estados Unidos que o debate têm sido colocado mais recentemente (desde os anos setenta).

Por todo mundo foi possível observar um fenômeno quase universal: o da reabilitação/requalificação dos centros das cidades - em particular das cidades maiores, mas também de numerosas cidades médias - por iniciativa dos poderes municipais. Certamente, essas reabilitações/requalificações não são homogêneas em todos os casos: em um mesmo país, há grandes defasagens de tempo. Ao observar a Europa e a América Latina por exemplo, a defasagem é, em geral, de cerca de trinta anos, o que faz com que as experiências de alguns lugares possam permitir avaliações e balanços - sobre seus sucessos e fracassos - e reflexões que contêm ensinamentos preciosos.

Interessada pela relativa contemporaneidade desse fenômeno nos dois continentes, busquei seus argumentos fundadores em alguns desses casos, pelo menos.

Parece possível afirmar que, se, na Europa, parte desses projetos tenha correspondido à reconstrução, a maior parte deles dentre eles tenha coincidido com um certo enriquecimento dos assalariados e a diversificação dos empregos urbanos do terciário, nos anos de 1960. Foi possível observar diferentes e sucessivas etapas nos programas de reabilitação/ requalificação das grandes cidades que subentenderam mudanças ideológias no espírito de seus elaboradores. Na América Latina, deve-se à Unesco a difusão, durante os anos de 1970, do pensamento sobre a reabilitação ou reciclagem de monumentos. Era dessa a tarefa que, além do mais, a própria Unesco se incumbia nessa época; entretanto, a emergência dos regimes democráticos em âmbito nacional, os processos de decentralização postos em marcha em todos os países e os governos locais frequentemente animados por uma dimensão social resultante de partidos que se apoiaram nas lutas urbanas nos anos de 1980, introduziram uma preocupação social suplementar. Essa preocupação parece estar presente em várias municipalidades da América Latina, não como cópia de um modelo mas como um quadro de referências, 
entre as quais o planejamento estratégico que se constituiu como referência onipresente.

A preocupação dos urbanistas em intervir nos centros urbanos não é nova. Ao menos na Europa, estão impregnados pelo valor simbólico dos lugares o que contribuiu para difundir prestígio e/ou notoriedade àqueles que intervêm na sua transformação. As grandes reformas urbanas - como a de Haussmann e suas emulações pelo mundo, assim como o pensamento higienista - são prova disso. Pode-se dizer que a grande ruptura com essa preocupação foi contemporânea, por um lado, à difusão da Carta de Atenas e, por outro, com um modelo espacial da cidade fordista.

Entretanto, malgrado esse episódio de muita importância, a vivacidade das representações simbólicas dos centros das cidades não se desvaneceu. Eles não se tornaram não-cidades, espaços vazios. Trata-se apenas de que eles não respondem aos imperativos residenciais e de produção do fordismo. Estavam fora do modelo funcionalista e evoluiram em um quadro que podia naquele momento aparecer como um quadro de desordem.

Hoje, representações muito negarivas, de acordo com os grupos sociais ou os fragmentos de classe social, e representações positivas (ligadas à identidade, à pesquisa cultural e estética) dividem o campo das representações. É por isso que se pode falar de uma «volta à cidade» ${ }^{1}$. Essa é uma proposição que diz respeito principalmente às cidades da Europa e da América Latina. Sustentouse ainda a idéia de que essa volta à cidade diria respeito somente a algumas camadas bastante identificáveis da população, o que leva a admitir que a noção de gentrificação tem sentido.

Isso me conduz a enunciar alguns paradigmas, já que se trata de dar aqui um quadro geral da problemática da requalificação dos centro históricos/ centros da cidade. Não é necessário mencionar que essa problemática qualificada nesse momento na América Latina como «integralidade das políticas urbanas de reabilitação dos centros urbanos» é também pluridisciplinar. Assim, para dar conta de sua complexidade, é necessário desconstruí-la. Por isso serão brevemente apresentados: a requalificação na visão urbanistas, entendida como ação reformadora; a requalificação vista pelos economistas, que se coloca na perspectiva dos termos do mercado e da propriedade imobiliária; a requalificação vista pelos sociólgos vista nos termos das representações, dos atores e das classes sociais. Os geógrafos e os historiadores, por sua vez, tentariam articular essas diferentes visões ou fazer emergir os paradoxos que delas emanam.

\section{Alguns princípios enunciados pelos urbanistas e pelos profissionais do urbano}

Tendo em vista alguns enunciados presentes nos projetos, pode-se dizer que três princípios podem dar conta da atualidade tal como é encarada pelos urbanistas, pelos profissionais do urbano e pelos que detêm o poder de decisão. Tanto na Europa como na América Latina, eles programam a requalificação (um conceito associado ao de «heterogeneidade sócio-espacial», surgido principalmente na Europa) e estão encarregados de exprimir seus projetos aos atores sociais «participantes» que surgiram primeiramente na América Latina². Situam-se em um intervalo temporal mais ou menos definido e seu projeto deve conciliar o social, a cultura e o mercado. Tentam combinar em um período determinado o reconhecimento de uma situação vista como caótica ou de crise e os imperativos de uma visão integrada de aglomeração urbana, apesar do abandono generalizado da idéia de planejamento e da perspectiva de correção no tempo de um projeto, os funcionamentos problemáticos herdados das tendências históricas. As classificações da Unesco impuseram, ainda, limitações que sem dúvida facilitaram algumas decisões relativas às prioridades; o não reconhecimento dessas mesmas classificações ofereceu também mais autonomia na definição das prioridades Na medida mesma em que a história de cada cidade mereceria ser contada já que a identificação dos atores suscetíveis de intervir em um projeto e seus níveis de intervenção, assim como as diferentes relações entres esses atores são diferentes, buscarei estabelecer os métodos e/ou as injunções que são frequentemente encontradas, mesmo quando defasadas no tempo conforme a cidade e o país. Para além de um discurso excessivamente formal sobre a cidade e a memória, no qual o imaginário de quase todos pode ser reconhecido, a reabilitação e a renovação 
acabam por se associar à idéia de desenvolvimento sustentável e, por seu intermédio, incluem uma dimensão ideológica: recriando as condições de durabilidade dos centros das cidades, contribuindo para exorcisar a crença de uma precariedade social que invade a vida urbana.

Por outro lado, o projeto urbano - especialmente em relação a um passado no qual a idéia de planejamento era dominante - é, hoje, muito circunscrito. Refere-se a um centro histórico, a um perímetro de intervenção, a uma determinada zona... tantas delimitações que permitem recorrer à concretização de uma idéia de " ciclo de vida» de uma operação e por extensão de seu sucesso ou fracasso. Segue-se, então, a requalificação por meio de princípios simples que põem em ação instrumentos estruturais e financeiros muito complexos. E eis aqui três deles, ainda que possa haver outros : em primeiro lugar, a contitnuidade urbana: trabalha-se sobre um projeto muito espacializado, mas não necessariamente criando guetos; é preciso portanto facilitar os acessos e as trocas, é preciso preencher os vazios. Um segundo princípio, que frequentemente se torna um imperativo: manter ou criar as condições da mistura - seja espacial, seja das atividades - e da mistura social, relativa às camadas sociais, às classes de idade, de profissões; na França, fala-se mesmo, nesse momento, de mistura étnica. A heterogeneidade espacial é supostamente impossível sem a heterogeneidade social. Remeto-me aqui aos esforços um tanto desordenados da prefeitura de Paris para criar uma espécie de mistura espacial no centro da cidade, pela renovação rápida das atividades culturais para bloquear a tendência à museificação dessa cidade que recebe a maior quantidade de turistas do mundo e que, em parte graças a eles, dá ainda a impressão dessa heterogeneidade quando nela se passeia.

Como já mencionei, a mistura ou heterogeneidade se tornou uma obrigatoriedade do ponto de vista político, sobretudo nas prefeituras que desenvolvem dimensões sociais e democráticas. A expressão heterogeneidade ou mistura ( em francês mixité) existe em muitos países e em várias línguas. Diz-se social balance nos Estados Unidos, mixité no Canadá, social mix na Ingleterra e na Austrália.Na França, falou-se em reequilíbrio social ; depois de uma carta de 1972, a palavra mixité aparece. E mesmo que os sociólogos se insurjam contra esse imperativo sempre presente - sobretudo trinta anos depois que a palavra aparece - e malgrado a dificuldade crescente de ascensão social, ainda assim é preciso reconhecer que os poderes constituídos tiveram necessidade de uma certa utopia ou ficção.

Um terceiro princípio que merece também ser mencionado é o de estratégia, pois está fortemente presente nas políticas urbanas na América Latina. É possível que a forma de sua enunciação tal como se segue signifique uma redução: um porjeto de renovação urbana, nesse caso de um centro histórico, visa um objetivo que faz do poder público o agente regulador do projeto. Esse projeto tem um tempo de vida no coração do qual se recorre a diversos intrumentos de ação, em particular a parceria público-privada. Durante seu tempo de vida, ele deve ser capaz de ser posto em questão (de ser questionado) e de se adaptar às condições de uma demanda ou de uma proposição nova.

Para concluir esse item: o uso dos princípios por parte dos profissionais associados à reabilitação pode mudar o curso, pela ação reformadora que pretendem empreender sobre um espaço dado, das grandes tendências sociológicas e econômicas, como por exemplo as injustiças criadas pelo mercado e a segregação espacial, bem como tendências por vezes consideradas como inelutáveis. Seria possível acreditar nisso caso se observasse algumas experiências; mas não se pode deixar de pensar que as categorias da ação pública são duais e simplificadas e mascaram as que, dentre elas, operam por um tempo mais longo.

\section{A Reabilitação de um ponto de vista econômico}

A recuperação de edifícios antigos de uma cidade é mais frequente nos dias de hoje, por oposição ao projeto funcionalista, que tinha força nos anos 1960. Essa observação pode remeter a uma questão de economia espacial cuja argumentação repousa em observações concretas: a divisão do espaço urbano em fragmentos de territórios que ganham e outros que perdem. Durante um período bastante longo, os centros históricos da América Latina, ao contrário de algumas cidades latino americanas, perderam mais de suas atividades próprias que as cidades européias e se despovoaram mais 
3. Ver Vincent Renard, Les conditions économiques du renouvellement urbain, à paraître 2006

4. Ver Allen Scott, L'économie culturelle des villes, Géographie, Economie, Société, vol.1 n¹, 1999 rapidamente. O processo ainda não foi revertido. É preciso, portanto, aplicar remédios diferentes daqueles que foram utilizados no passado.

Entretanto, na medida em que a reabilitação deve ser «integral» e mais ainda um «elemento de sustentabilidade», ela deve conciliar um projeto econômico eficaz, uma preocupação com o reequilíbrio social (fórmula utilizada desde os anos setenta na França, até que a palavra mixité aparecesse), com a qualidade ambiental e com a segurança. A combinação entre esses elementos, preconizados pelo Banco Mundial e pelo BID, é contudo difícil pois suas lógicas operatórias são diferentes. Se a idéia de integralidade remete à vontade política, a idéia de eficácia ou sustentabilidade econômica preconiza a volta das zonas empobrecidas para o mercado. Esta ainda é a história de muitos dos centros urbanos hoje em dia. Como os poderes públicos poderiam contribuir para uma volta dos centros urbanos às atividades de mercado? Retirando os obstáculos institucionais, jurídicos, relativos ao estatuto de propriedade das zonas que têm um valor de mercado potencial, apoiando-se na centralidade geográfica, na memória e na cultura, que um marketing urbano bem elaborado é capaz de reeditar ${ }^{3}$. Nesse contexto, que supõe a articulação entre público e privado e em uma lógica puramente econômica, observa-se a constituição de regras do jogo financeiro, jurídicas e econômicas que permitem ao setor público recuperar algumas vantagens suscetíveis de serem redistribuídas para o bem estar da população. Há experiências micro-locais que podem aparecer como bem sucedidas aos olhos dos economistas. Até que ponto os poderes públicos podem se engajar nessa lógica que pressupõe retorno apenas a longo prazo? Pode-se dizer, por outro lado, que as lógicas de diferentes âmbitos de poder não são sempre as mesmas; essa é uma longa história nos países europeus, mas, acredito, também nos países latinoamericanos. As intervenções realizadas em uma mesma cidade podem dar lugar a uma nova divisão dos espaços - entre aqueles que perdem e aqueles que ganham, na mesma medida em que a idéia de planejamento se enfraquece na onda de rejeição ao funcionalismo.

Na América Latina, a intervenção pública sobre a questão imobiliária deveria desempenhar um papel importante nos projetos de reabilitação, pois ela aparece como o único modo de lançar programas de habitação popular, uma idéia presente em muitos governos locais sensíveis à questão social, notadamente no Brasil, nas cidades governadas pelo Partido dos Trabalhadores (PT). Mas cada história urbana tem, nesse âmbito, sua especificidade. Pode-se afirmar, nesse momento, que os pesquisadores podem contribuir com algumas conclusões válidas, mas somente em função de cada contexto particular. O segundo elemento da abordagem econômica da requalificação se assenta, da perspectiva da retomada das atividades, na coabitação entre atividades modernas e tradicionais. A promoção das atividades ligadas à cultura acontece em toda parte. Por que essas atividades ligadas à cultura aparecem como pósmodernas e pós fordistas? Por que criam muitos empregos? Por que são um micro mercado de trabalho flexível e dinâmico em função do desenvolvimento do turismo, por sinal muito variável em volume de acordo com as cidades ou de acordo com sua natureza local, nacional, estrangeira, etc. Entretanto, pode-se fazer a seguinte afirmação: são esses lugares que permanecem sendo, em uma certa medida, responsáveis pelas distinções entre culturas; trata-se, então, de um potencial de valorização ${ }^{4}$.

Ora, esse desejo de distinção é também uma alternativa à uniformização dos modos de vida da classe média mundializada frente à uniformização espacial que parecia ser o resultado inelutável do período fordist. Por isso os centros urbanos permitem a convergência entre a concepção material de um produto especificamente ligado ao lugar e seu conteúdo cultural. O risco e o perigo é o de que os centros das cidades se restrinjam a esse papel e, nessa medida, não possam mais promover uma dimensão de criação, vinculando-se somente à rentabilidade, talvez efêmera, da atividade cultural.

Para desenvolver esses setores de atividades, recorrese a uma grande diversidade de sistemas de financiamento : formas de estímulo financeiro, a prática das franquias, etc. Mas há também um outro aspecto econômico ligado à reabilitação que é o da promoção da pequena empresa. Com efeito, nas cidades européias, a reabilitação é consequência de numerosas pequenas empresas que desenvolveram 
um saber particular e empregam uma mão de obra abundante e pouco qualificada no início, inclusive através de programas de reinserção. Note-se que em um programa de reabilitação é raro que haja convergência evidente entre a oferta residencial e os empregos propostos, a não ser em alguns microespaços cuja requalificação é justificável (e explicável), como por exemplo, alguns bairros com caráter étnico.

Tentei apresentar algumas variáveis que os economistas priorizam quando se trata de renovação urbana, que associa a retomada do mercado e a intervenção pública. Busco, assim, diversificar o campo dos agentes de intervenção - e acredito que isso se justifica com respeito à tendência que se difunde na América Latina, de acordo com a qual a aposta na requalificação das cidades não pode ser apenas a do grande capital como SLIM no México, ou Soros em Buenos Aires ou a do Banco de Boston em São Paulo.

\section{As classes sociais e a dimensão social da reabilitação}

Para encerrar essa reflexão e antes de colocar algumas recomendações, gostaria de lembrar o debate sobre o risco de gentrificação dos bairros antigos, que se constituiu como objeto de uma produção abundante tanto do ponto de vista da sociologia quanto da geografia, nos Estados Unidos e na Ingleterra e, em menor proporção em outros países da Europa e na América Latina. Ainda assim, o debate se fez presente em todo lugar: a palavra gentrificação foi afrancesada; ela existe também em espanhol e em português. Gostaria apenas de discuti-la da forma que se segue: os especialistas na questão viram a gentrificação como um processo que resultava da estrutura do mercado imobiliário e do comportamento dos atores privados (especialmente de algumas classes médias, denominadas, na América Latina, classes médias superiores), recuperado e erigido em política urbana pelas municipalidades. E esse processo tinha como finalidade valorizar seus centros, tornar as cidades mais atraentes e favorecer sua reconversão econômica ${ }^{5}$.

5. Catherine Bidou-Zachariasen, Introduction, in : Catherine Bidou-Zachariasen (dir.) Retours en ville, Descartes, 2003 positiva de «melhorar o estatuto social dos bairros». Mas os discursos sociais enunciados pelas prefeituras não pôde esconder, de um lado a subida considerável dos preços dos terrenos conhecidos apenas, ao menos em alguns centros urbanos, pelos promotores imobiliários e pelos cartórios ; de outro lado, a expulsão de habitantes das camadas populares e especialmente dos idosos que se beneficiavam do regime social de aluguéis antigos.

A realidade da gentrificação anteriormente considerada como positiva, em uma primeira etapa, adquiriu hoje uma conotação negativa; ela serve apenas à classe média superior. Depois de quinze anos, uma nova palavra apareceu em várias línguas e países, no discurso dos urbanistas e das políticas - é a palavra heterogeneidade (mixité) declinada como mistura social, mistura espacial, sendo que uma se pressupõe à outra. Supõe-se que ela exprima uma vontade política de inflexão das tendências excludentes e anti-sociais do mercado.

O que gostaria de observar para finalizar é que a gentrificação e a mixité exprimem processos que o tempo e a vontade política podem reorientar. Não são conceitos congelados, nem mesmo consolidados. Em algumas cidades européias, são até mesmo considerados ultrapassados. Uma nova divisão sócioespacial do espaço se desenha em cidades como Londres e Paris, onde uma nova camada social, rica e com atividades mundializadas, em particular especializadas em atividades culturais, de comunicações e de moda, parece se transformar nos únicos compradores do parque imobiliário residencial nos centros das cidades. Ao mesmo tempo, os habitantes das periferias, onde se confundem camadas médias e populares, frequentam esses espaços aos sábados e domingos.

O que pensar desse processo? Ele é passível de tranferência para outras cidades, na América Latina, por exemplo? A resposta mais frequente é não e isso por várias razões : a promoção imobiliária ligada ao mercado não conferiu aos centros históricos o caráter de espaços residenciais. Não existe uma classe média, ou antes uma classe média superior suficientemente numerosa para que a partir dela se constitua uma fração que possa se identificar coletivamente com o urbano constituído pelo 
passado fazendo dele um valor comum, mesmo que seja inteiramente reabilitado. É assim, frequentemente, a vontade política das prefeituras que intervêm nos programas de habitação social ou, em certos casos, simplesmente, mais baratos. Enfim, os programas de habitação social são compatíveis com o mercado de trabalho que oferece o desenvolvimento de atividades modernas de serviços ? Creio que para responder a todas essas questões, o conhecimento das experiências é importante, mesmo que já existem alguns conhecimentos ainda parciais sobre esses temas. As experiências permitem também compreender que alguns processos podem se assemelhar mas não se desenvolvem de modo idêntico. Descontruílas é essencial pois há alguns ensinamentos que circulam entre os especialistas. 